\title{
Market-resource Links and Fish Vendor Livelihoods in the Upper Zambezi River Floodplains
}

\author{
James G. Abbott • Lisa M. Campbell • Clinton J. Hay • \\ Tor F. Næsje • John Purvis
}

Published online: 16 January 2007

(C) Springer Science + Business Media, LLC 2007

\begin{abstract}
This paper examines small-scale fish vending in a southern African floodplain from two perspectives: as a link between natural resource use and consumption, and as a livelihood in itself. We used a combination of observation, surveys and semistructured interviews in a market in Katima Mulilo, Namibia, to determine sources of fish, preferences and constraints to vending, average investment and profit, as well different routes into fish vending and perceptions regarding vending. Most vendors come from fishing households, but their stock is often an accumulation of purchases
\end{abstract}

J. G. Abbott $(\bowtie)$

Department of Geography and Urban Studies, Temple University, 309 Gladfelter Hall,

Philadelphia, PA 19122-2585, USA

e-mail: jabbott@temple.edu

\section{M. Campbell}

Nicholas School of Environment and Earth Sciences,

Duke University,

135 Duke Marine Lab Rd,

Beaufort, NC 28516, USA

e-mail: 1campbe@duke.edu

\section{J. Hay}

Ministry of Fisheries and Marine Resources,

Private Bag 2116 ,

Mariental, Namibia

e-mail: cjhay@mweb.com.na

\section{T. F. Næsje}

Norwegian Institute for Nature Research,

Tungasletta 2, NO-7485,

Trondheim, Norway

e-mail: tor.naesje@nina.no

J. Purvis

Lake Victoria Fisheries Organization,

P.O. Box 1625, Jinja, Uganda

e-mail: jpurvis@lvfo.org from other fishers. There is little evidence of formal arrangements between fishers and vendors, yet most adapt to the highly variable natural and social environments of the region. Although all vendors ranked selling fish as their most important livelihood activity, a wide range of investment and profit exists among individuals. Our findings indicate that fisheries management proposed for the area must be developed with a careful understanding of how changes in access and use will affect vending livelihoods.

Key words Markets · artisanal fisheries · livelihoods · floodplains · sub-Saharan Africa

\section{Introduction}

Throughout urban and rural sub-Saharan Africa, a large amount of the exchange in locally produced food takes place through small-scale vending (Fafchamps, 1997). Analyses of small-scale vendors and the markets in which they operate have typically asked (1) how this activity mediates linkages between resource use and consumption (e.g., Bowen-Jones et al., 2003; Mendelson et al., 2003) or (2) how small-scale vending can be understood as a livelihood itself (e.g., Brockington, 2001; Green, 1999). Such inquiries are important because conservation and development perspectives towards small-scale vending in general are often ambivalent (Agrawal and Yadama, 1997; Becker, 2000). In terms of a link between exploitation and consumption, several authors have argued that the commercialization of an open-access resource, even at a limited scale, can potentially lead to unsustainable levels of exploitation (e.g., Wilkie and Carpenter, 1999). Livelihoods that include smallscale vending may represent an individual's marginality or affluence, as well as the relative scarcity or abundance of a 
resource. Understanding market commodities, dynamics and participants can allow us to better grasp the broader environmental, social and economic processes taking place and how both livelihoods and resource use can be made more sustainable (e.g., Ellis, 2000).

In artisanal fisheries, catches frequently have both consumption and commodity values, making a distinction between subsistence and commercial activities difficult (Allison and Ellis, 2001; Bækgaard and Overballe, 1992; Berkes et al., 2001; Klein, 1999; Platteau, 1989). This paper examines small-scale fish vending, both in terms of how it links resource use and consumption, and as a livelihood, using a case study of a market in Katima Mulilo, Namibia, in the upper Zambezi floodplain in southern Africa (Fig. 1). We chose this setting because while African floodplain fisheries provide income and protein to large numbers of people, little is known about floodplain fishery biology or its role in livelihoods. An understanding of how a market associated with a floodplain fishery operates therefore provides important insight to both areas.

This paper is organized as follows: First, we review recent literature on small-scale vending and themes of resource-consumption and livelihoods. We discuss the characteristics of small-scale fish vending and suggest how vending in coastal and lake environments (where the majority of studies have taken place) may differ from floodplain environments. We then describe the results of a longitudinal study of a fish market associated with the upper Zambezi floodplain, focusing on the commodity chains and the demographic and livelihood characteristics of the vendors. We conclude by considering to what degree our case study reflects descriptions of small-scale fish vending found elsewhere, as well as the potential impacts of fisheries management policies.

Small-scale Vending as a Link Between Resource Use and Consumption

From an environmental perspective, the linkages between markets and resource use have often been portrayed in a negative light. This may be traced at least in part to idealized Western perceptions of rural economies as bucolic, selfsustaining and unchanging (De Janvry et al., 1991; Li, 2002; Holt, 2005). Reasoning follows that with the encroachment of outside markets, local production patterns change in order to meet expanded levels of consumption existing in regional and global spheres. Markets therefore cause the scale of resource use to change in two ways: as users strive to meet both subsistence and commercial demands, and as introduced technologies make extraction more efficient. It is therefore important to distinguish between changes in the scale of resource use taking place due to population-driven increases in fishing effort (as more individuals enter a fishery), and investment-driven increases, where more gear, usually of greater efficiency, is introduced into a fishery (Jul-Larsen et al., 2003)

Researchers have also argued that an increased linkage to markets can lead to patterns of use either beyond the benefit
Fig. 1 Location of the study site.

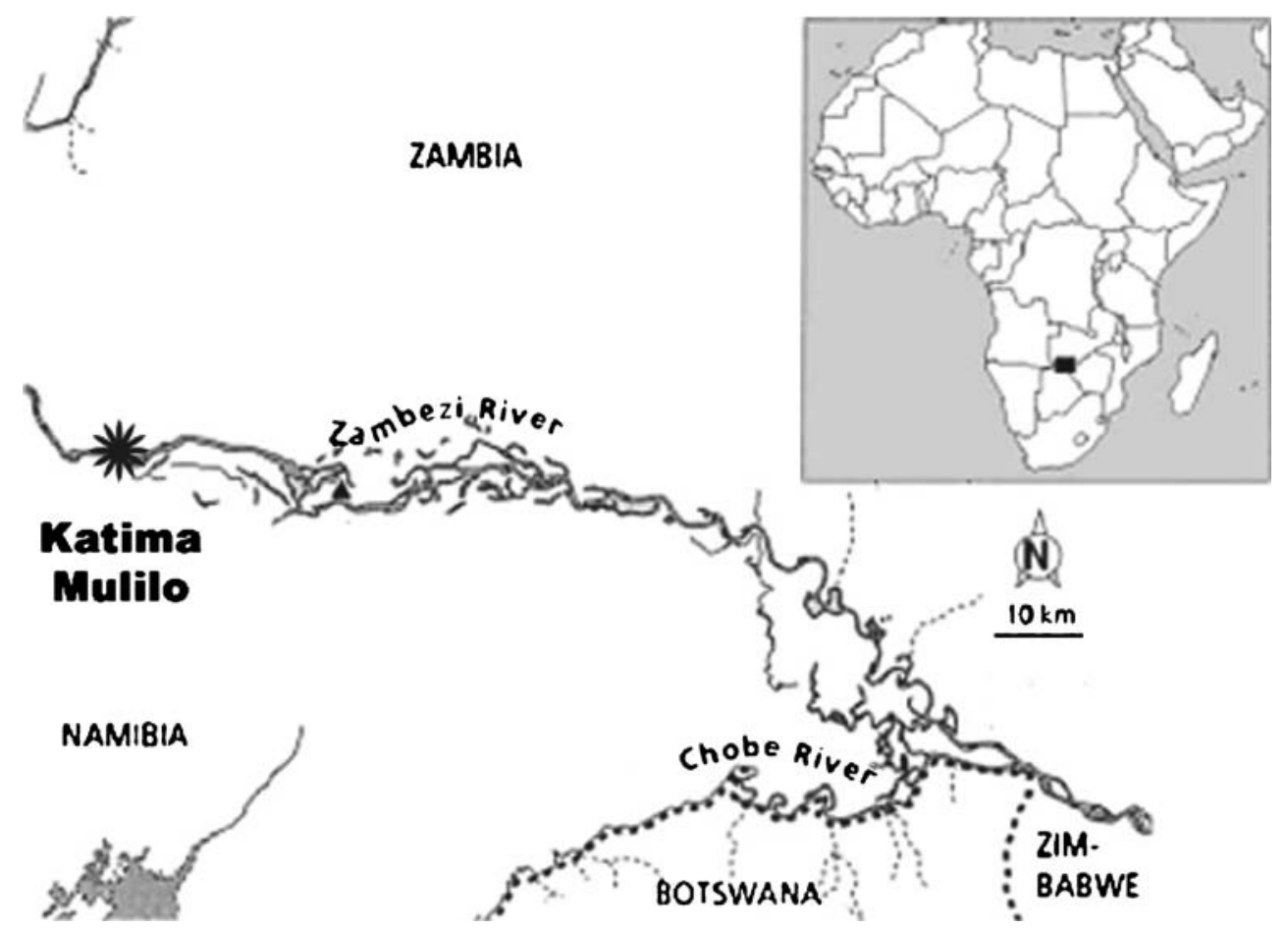


and influence of those living closest to these resources (e.g., McGrath et al., 1993; Walker, 2001; Godoy et al., 2004; Vadez et al., 2004), or subject to capture by local elites et al., Little and Brokensha, 1987). In these and other scenarios, benefits are lost as rents accrue largely to agents located in distant markets, and the ability of local producers to calculate and mitigate risks is diminished by the increased geographical and social distance of new market arrangements.

Similar reasoning implies that as individuals within a community assume the rational economic personalities presumably required to function in a market system, the ability for local institutions to effectively manage resources is compromised (Jentoft, 1998). Patterns of resource use that benefit individual gain become preferable to cooperation, and the management structures based on common interest become less applicable, leading to a breakdown in the 'moral economy' (Agrawal and Gibson, 1999; Becker, 2000). In an extension of this reasoning, as resource users are linked into a market system, they themselves become more reliant on commodities, and hence must devote additional time to subsistence and income generation (Godoy et al., 2004).

The role of small-scale vendors in the market-resource narrative of increased extraction and declining management capacity has been ambiguous. On the one hand, small-scale vendors can be seen as a vanguard of market encroachment, or merely a relatively inefficient facet of it, prone to the same consequences of co-option and marginalization as the resource users themselves (e.g., Skjønsberg, 1992; Hapke, 2001). In extreme cases, linkages to larger markets and economies of scale can cause a depression in local prices, as seen for example in the flooding of local dairy markets in East Africa with cheap powdered milk (Staal et al., 1997). On the other hand, small-scale vendors conceivably act as a buffer to external market forces, by mediating effects and asserting control at the local level (e.g., Ensminger, 1992; Clark, 1994; Chalfin, 2000). From a management intervention perspective, in the former view, small-scale vending is an activity that can compromise resource sustainability, whereas in the latter view, it is a potential conduit for a more equitable distribution of returns.

\section{Small-scale Vending as a Livelihood}

Recent efforts to understand tangible and intangible qualities of livelihoods, particularly in rural developing areas, have provided a more nuanced yet frequently contrasting understanding of small-scale vending (e.g., Green, 1999; Brockington, 2001; Perez et al., 2002). The variety of opinions mirrors a similar discussion regarding the positive and negative consequences of livelihood diversification (e.g., Ellis, 2000). Due to its adaptability, low amounts of commodities and uncomplicated regulation, small-scale vending can be seen as a way to accumulate capital and convert resources with limited entry and opportunity costs. This adaptability has also been perceived as a way of managing economic uncertainty (see, for example, Chalfin, 2000).

Alternatively, the marginal nature of both the participants and the products suggests that small-scale vending manifests both the restrictions inherent in many patriarchal societies, as well as the growing need to generate income in an increasingly monetized environment. In their study of bushmeat vending in Cameroon, Perez et al. (2002) conclude that while it may be a liberalizing and wealth accumulating activity for women, it is still undertaken at a comparative disadvantage to men, who have more time, mobility, education and access to credit. Green (1999) echoes this sentiment in her examination of beer brewing in Tanzania. Vending is a way for women with limited livelihood options to access a largely male dominated economy, and as such is "both an indication of political weakness and a potentially empowering economic strategy" (Green, 1999; p. 419). Brockington's (2001) research into milk vending in Tanzania resulted in a similarly equivocal conclusion:

The dual purpose of the milk trade-as a means of subsistence for poor pastoralists and as a source of income for women- means that an increase in milk trading is hard to interpret. It could be an indication of poverty, or the result of women earning their own income. It could be both. (p. 310)

\section{Small-scale Vending and Artisanal Fishing}

The issues of market-resource links and livelihoods significance also resonate within small-scale vending associated with artisanal fisheries. Andersson and Ngazy (1998), in their study of artisanal fishers of coastal Tanzania, found that those living in villages closer to tourist areas increased the amount of time spent fishing in order to supply the lucrative demand for fresh seafood. Similarly, Allison and Mvula (2002) suggest that fishing effort at Lake Chilwa, Malawi, increased as the region as a whole became more integrated in the market economy. Skjønsberg (1992) describes a village near Lake Mweru in Zambia that had previously been the centre of a thriving fish trade but was bypassed by a new feeder road. While the road made the village more accessible to new markets, it also allowed trucks to access landing points at the lake itself.

No clear trends emerge concerning small-scale fish vending's significance as a livelihood. Medard et al., (2001) state that the vendors in Lake Victoria are dominated by single, divorced and widowed women, a demographic subset frequently associated with poverty. However, Dolan 
(2002) reports that in a region of Uganda, fish trading is a prestigious livelihood among women and most valued as income generator. In the Indian port of Goa, Rubinoff (1999) shows that there is a difference in how fish vending is perceived depending on how status is measured. From a social perspective, vending is associated with lower castes. However, increased catches due to new technology mean that a vendor can be very important and hence gain prestige if she can capitalize on this new supply of fish. In Kerala, Hapke (2001) demonstrates that as the supply of fish has changed to bulk landings and landings that come from adjacent regions of India, distribution has become stratified, often marginalizing vendors with less financial and social capital.

The majority of studies examine small-scale fish vending in marine or lake environments. Less attention has been given to small-scale fish vending in sub-Saharan Africa's floodplains (FAO, 1996; Welcomme, 1999; Geheb and Sarch, 2002). However, important biological, social and economic characteristics distinguish floodplain fisheries from those in marine or lake environments. These differences concern the productivity and variability of the fishery, as well as the fishers that exploit it.

\section{Variable Productivity}

Floodplain fisheries often have high levels of productivity, but this productivity is highly variable due to seasonal flooding as well as longer-term climatic trends (Jul-Larsen et al., 2003). Lakes and to a certain degree coastal fisheries may also experience changes in fish biomass and catchability. However, the spatial and temporal variation in the floodplain environment is by nature much more dramatic. The concentration and abundance of different fish species also changes over space and time due to constantly changing habitat and predator/prey balances (Laë, 1997; Welcomme, 1999). Thus, patterns of exploitation change as fishers adapt to the changing aquatic landscape (Welcomme, 1985). Moreover, floodplain inhabitants typically practice a wide range of livelihood activities in addition to fishing, largely dictated by the same cyclical patterns of precipitation and inundation. As a consequence, labour bottlenecks can occur during certain times of the year, where individuals divide their time between fishing, farming, livestock, and off-farm labour (Adams, 1992, see also examples described by Sarch, 1996; Sarch and Birkett, 2000; Shorr, 2000 and Winklerprins, 2003).

\section{Commodity Chains}

The distinctions apparent in floodplain fisheries also extend to post-catch activities. In coastal or lake fisheries, landing sites for catches are well defined and often permanent, with fishers and vendors concentrated in the same place. Consequently, the level of competition (among or between vendors or fishers) is likely to be high. Alternatively, fishers and vendors may choose to enter into arrangements in order to limit risk and secure credit and supply, respectively (e.g., Vercruijsse, 1983; Gibbon, 1997; Walker, 2001). There may also be a certain level of organization amongst vendors in terms of setting the daily prices for fish and arbitrating disputes. Beyond the immediate market, the permanence of landing sites usually leads to the establishment of networks of transportation and intermediaries for the distribution of fish.

By contrast, landing sites within a floodplain are both widespread and likely to change location over time, sometimes at a relatively rapid rate, according to the degree of inundation. Hence, with only small numbers of fishers using each landing site, it may be difficult for fish vendors to know where, when and if fishers will land their catch. Tvedten and Hersoug (1992) argue that due to the scattered nature of fisheries in floodplains, these systems are less likely to be linked to outside systems of consumption and production. Overall, the extent to which the complex arrangements seen in lake and marine fisheries in Africa (e.g., Gibbon, 1997; Marquette et al., 2002; Overå, 2001; Walker, 2001; Overå, 2003) are replicated in floodplain fisheries is largely unknown (but see Gordon, 2003 and Musambachime, 1995, for examples of commercial level exploitation and distribution in a floodplain fishery).

\section{Case Study: The Ngweze Market, Katima Mulilo, Namibia}

The majority of fish vending in Katima Mulilo takes place in the largest and most central market, the Ngweze Market. While there are other markets located in the peripheral townships, these markets are limited in the range and volume of produce sold, as well as the number of vendors (Hilger, 2002). Since its beginnings in the 1950s, the Ngweze Market has been the focus of small-scale commerce, despite the successive establishment of independent general stores and South African franchise grocery outlets. The market's original site was closer to the post office, however in the 1970s it was moved to its present site, adjacent to the hospital and the local taxi and bus rank.

Many descriptions of markets in Africa emphasize the role vending plays for meeting the livelihood and consumption goals of the relatively poor. However, customers who visit the Ngweze Market do not appear to be limited to a specific income bracket or social class (J. Abbott, personal observation). While the majority of the customers are "average" (i.e., with limited disposable income), relatively well-paid civil servants and consultants frequently visit the market, particularly to purchase fish. Individuals traveling to the capital by plane will frequently take a cooler full of large fresh fish for friends and family. 
General Market Arrangements and Patterns

The market is open from 7 A.M. to 6 P.M. each day. Vendors typically enter the market through the official entrance at the south end. A representative from the Town Council is usually present from 8 A.M. to noon (the peak arrival time for vendors) to collect a daily market fee ( $2 \mathrm{~N} \$$ per vendor at time of research) and issue receipts. In theory, the fees are to be applied to market maintenance and overnight security. However, recently vendors have refused to pay, claiming that security has been very poor and that theft of produce had occurred in the evening hours. This lack of confidence reflects larger fiscal and management problems that the Katima Mulilo Town Council has recently experienced.

Within the market enclosure, stalls are distributed according to type of produce sold. The fish vending section consists of a series of eight long concrete benches, approximately $0.75 \mathrm{~m}$ wide and $18 \mathrm{~m}$ long and $1 \mathrm{~m}$ high. The posts supporting the roof act to demarcate the benches into six different segments per bench, which in turn are divided into two. Hence, the stalls could conceivably accommodate at least 96 fish vendors. Prior to the construction of the fish stalls in 2001, fish were sold in the east corner of the market, either on crude stands or on pieces of cardboard laid on the ground, often with limited shade.

While this study focuses on fish vending, it is useful to describe some of the other vending activities in the Ngweze Market. One general characteristic of the vendors is that they are almost entirely female, $96 \%$ as measured in a 2002 survey (Hilger, 2002). The goods available reflect the varying local, regional and international sources of commodities. In addition to food, there are several stalls offering commodities and services that range from second hand clothing, chitenges (printed sarongs from Tanzania and Zambia), furniture, household implements, tobacco and cigarettes (from Zambia and Zimbabwe) and money exchange.

\section{Research Questions}

The high levels of potential human and natural variability found in floodplain fisheries and livelihoods leads us to pose the following four questions regarding small-scale fish vending in these environments:

1) What is the commodity chain linking fish to market in the Upper Zambezi River floodplains?

We examined the arrangements between fishers and vendors for the accumulation, selection, purchase, preparation and transportation of catch for market. We also observed activities within the market, such as allocation of stalls, intra-vendor interaction and extra-regional distribution of catch.
2) Is market supply largely dictated directly or indirectly by seasonal factors, such as the natural variation in fish abundance or the variability in floodplain livelihoods?

We looked at the numbers of vendors occupying stalls at the market over the course of more than a year. We were also interested in vendor perceptions of the best and worst seasons for selling fish (if any), as well as the rationales behind these perceptions.

3) How do small-scale fish vendors respond to high apparent levels of uncertainty in fish supply?

As floodplain fisheries typically vary in the volume and composition of catches, we anticipated that small-scale fish vendors would have to be very adaptable. As such, we considered where vendors typically got their fish (i.e., from family, non-related fishers or intermediaries) and the frequency and ranking of different constraints to vending, such as transportation, getting enough fish, getting the right size of fish or getting the right kind of fish.

4) Are there any patterns in demographic or other characteristics of small-scale fish vendors that suggest vending can be characterized as a marginal or lucrative activity?

Demographic patterns seen in examples of small-scale fish vending are extremely broad. Returns from vending are potentially lucrative, yet at the same time, the limited investment required means that individuals and households with limited entitlements to other resources, such as women and female-headed households, could potentially participate. We collected data on gender, marital status, household position, incomes and personal histories to better understand fish vending as a livelihood activity.

In data collection and analyses, we distinguished between fresh and dry fish vendors in the market on the assumption that choosing between selling dry and fresh fish is the most basic decision that a fish vendor can make, independent of the quantity of fish available or the size or species of fish in the catch. It also involves the greatest distinction between opportunity costs, due to the time involved in and cost/ benefit ratios. Therefore we were interested if there were any differences in the responses to the questions above according to whether the vendor sold fresh or dry fish.

\section{Materials and Methods}

Data collection consisted of observation, market surveys (with three components), and semi-structured interviews with fish vendors at the Ngweze Market in Katima Mulilo, Namibia. All data collection activities that involved direct questioning of vendors were carried out in SiSubia or SiLozi with a translator who also acted as interviewer. 


\section{Observation}

Structured data collection described below was complemented by observation of vendor activity, particularly interactions between themselves, with fishers and in households, throughout 12 months of research by the lead author. Observations took place at the Ngweze Market during the course of market surveys and semi-structured interviews. In addition, observations were made during research on fishing livelihoods at riverside landing sites, during a household survey conducted throughout the floodplain and during a 3-day stay at the floodplain camp of a well-established high volume fresh fish vendor. These observations are the primary means of addressing research question no. 1, regarding commodity chains linking fish to the market.

\section{Market Surveys}

Market surveys took place every Wednesday at the Ngweze Market between June 2002 and October 2003. Market surveys included several components: recording market stall occupation and vendor distribution, recording data on fish species, length and price, and surveying a random sample of fresh and dry fish vendors.

\section{Market Stall Occupation and Vendor Distribution Surveys}

The number and type of fish vendors (i.e., whether they were selling fresh or dry fish) and which stalls they occupied at the market were recorded at 8 A.M. on the day of the survey using a stylized depiction of the market stalls. Recording which market stalls were occupied and by whom served two purposes. First, it facilitated the identification of randomly selected vendors. Second, the spatial distribution of different types of market vendors (i.e., dry/fresh) in addition to their absolute numbers could be recorded. Patterns in distribution yield important insight on how vendors assert claims to market stalls, especially when there are high numbers of vendors.

\section{Fish Species, Length and Price Surveys}

The number, species, length and price of fish sold by the randomly selected vendors were recorded during the weekly surveys. Survey members were trained in species recognition, using the species names in the local languages. In order to limit our intrusion, the data collection was guided by how vendors arrange their fish. Vendors generally aggregate their fish into three groups: bream (cichlids), catfish (siluriformes), and tigerfish/pike (characiformes). Within these groupings, vendors arrange fish that sell for the same price in piles. For each pile, the price was recorded, the numbers of fish in each species were counted, and the fork lengths of the largest and smallest fish of each species, plus a random sample of five individuals, were measured. The results were recorded on the survey form used for vendor surveys.

\section{Surveys with Fresh and Dry Fish Vendors}

Using the results of the market layout survey, a stratified random sample of ten fresh and ten dry fish vendors was made each survey day. Upon consent, the selected vendors were asked how the fish were obtained (i.e. from a family member or purchased), how long it took to accumulate their stock, costs of transport, as well as their investment and expected revenue from the fish they had for sale that day. Demographic data collected included marital status (married, single, divorced, widowed) and position in household (i.e., head of household, spouse, child). Vendors were also asked about their perceptions regarding the best and worst seasons to sell fish and the reasons behind this, the most important factors in getting to the market, the relative importance of vending to other activities and the number of years they had participated in vending.

To avoid survey fatigue, the survey form was altered in June 2002 to distinguish between vendors that were new to the survey and those that had already been interviewed at least once during the survey. Vendors in this latter group were randomly selected for survey, and were asked only about how and where they got their fish as well as transport costs, investment and expected revenue.

During the course of market surveys, several vendors raised concerns about how results might affect them, especially if the fish market was closed, or their ability to obtain fish was limited due to gear restrictions. In December 2002, copies of a two page summary of the results from the structured survey, translated into SiLozi, were laminated and distributed to vendors for comment. At the close of the market, a group of 12 vendors gathered with the survey team to discuss the results, comment on their validity, identify possible factors for the trends identified and generally discuss the benefits and constraints of fish vending. This exercise allowed us to ground check preliminary findings, provide context to these findings and allay potential fears regarding the implications of our research.

\section{Semi-structured Interviews}

Initial results from the structured surveys suggested that there were considerable complexities in fisher-vendor linkages, motives for selling, and changes in vending over time. A follow-up visit in November 2003 was made in order to conduct open-ended interviews with the different types of vendors. Interviews focused on themes of when and why the vendor started selling fish, who showed them how, if they had ever stopped, changes in the supply of fish, fisher-vendor 
relationships, frequency of selling, perceptions of being a fish vendor, changes in the fish market, ranked importance of different livelihoods and changes and how the record flood in March 2003 may have affected them. When possible, vendors were interviewed at a quieter location several meters away from the market stall. This was done to limit distraction as well as noise, as it was intended to audiotape as many interviews as possible. However, most vendors refused to be recorded, and hand-written notes were taken.

\section{Results}

\section{Getting Fish to Market: The Commodity Chain}

The starting point of the supply chain linking fish to market is naturally the fishers. High transportation and opportunity costs limit the benefits of direct fisher-market interaction, and we found it extremely rare for fishers to go directly to the market. Hence, the link between the fisher and consumer largely occurs either through kin-based relationships or vendors traveling the floodplains. Fishers will return with their catch to fishing camps or clearings along the riverside, either giving the catch to female relatives to process and sell, or selling it directly to traveling vendors. These landing points are scattered throughout the floodplain, each typically making up a small proportion of the total catch landings from the river.

In situations where fishers sell their catch to vendors, bartering is usually done regarding the size of fish, species and in some cases the condition (if the net was prone to predation by otters or crocodiles). In transactions observed during this study, the fish were generally sold in groups according to size and species (e.g., a pile of ten small bream). Vendors typically expected a discount if they bought large amounts, and would take turns making their purchases, rather than bidding on fish as a group. If there was not enough fish for all the vendors present to buy on any 1 day, then there is a general agreement that those who left empty-handed get to buy first the next time.

Vendors travel to the market in hired transport, usually a truck or sedan. They only take as much fish as they can carry, and hence the back of the vehicle is full of both vendors and produce. The price paid for transport is based on a fixed price per person, plus a variable price according to the weight and volume of the cargo. Some vendors go to market every day, having prearranged payment and pickup with an operator, but most go as opportunity dictates, and depend on there being enough space in the truck and being able to agree on a reasonable price with the operator. The tracks leading from the floodplain are sandy and flood quite quickly when the river level begins to rise in December. Vendors are then obliged during the flood season to either limit their purchases to areas reached by roads on dry land, or alternatively use dugout canoes (mokoros) to reach isolated fishing camps.

Upon arrival, vendors will pay their market fee and occupy a stall. Most fresh fish is displayed on wet hessian sacks. The distribution of fish vendors amongst the market stalls showed a consistent pattern over the sampling period. Generally, dry fish vendors aggregated to the west side of the fish market, while fresh fish vendors were at the east side. Those few fish vendors (or their relatives) who were observed at every survey event occupied the stalls closest to the centre of the southern end of the market. These established full-time fish vendors have broken chest freezers that serve as placeholders for the most preferred stall locations as well as for simply storing fish, and use ice (in limited quantities) to keep their produce fresh. This practice reflects an elementary hierarchy_although the general rule for stall occupation is first come, first served, vendors who have sufficient capital to invest in ice and coolers get the preferred stalls.

Changes in the amount of stock held by fish vendors during their stay are not directly a function of purchases. In cases such as kin-linked vending where vendors can ensure a supply of fish without having to be present to purchase them, they will sometimes arrange to have fish brought to the market. In addition, the arrival of a vendor bringing fresh fish will usually attract casual curiosity from other vendors who will sometimes buy fresh fish to augment their stock. Vendors faced either with other obligations or excess stock at risk of deteriorating will often sell at reduced prices to other vendors. Frequently, fresh fish that is no longer desirable is sold to dry fish vendors for processing, or is eaten by the vendors themselves (Purvis, 2002). Hilger (2002) and Purvis (2002) both reported that a majority of vendors experience stock deterioration to the point of having to discard fish.

The Ngweze Market has a limited level of organization, both for the market in general and for vendors of specific commodities. There is a market committee made up of representatives from each vendor group that in theory decides policy, collects funds and carries out maintenance as well as communicating relevant issues and concerns to the local government. However, the committee is apparently of limited importance to most vendors as it was rarely mentioned in interviews conducted during our research or in other related studies. Conflicts and general maintenance appear to be dealt with in an ad hoc manner as the need arises. The level of organization therefore seems to be very fluid, depending both on the relative costs and benefits of a potential decision and on the ability of individuals to assert influence or authority on vendors in general. However, there is a level of social cohesiveness amongst vendors. Vendors from the same area will occupy stalls next to each other. This is understandable, since many arrive in the same vehicles. If a vendor has to be away from the market during 
Fig. 2 Occupation of fish vendor stalls at the Ngweze market recorded on survey days, June 2002-November 2003, with corresponding flood level cycles. The solid line represents the trendline calculated from the running median. Surveys were not conducted on August 2nd, 2002, September 3rd and 25th, 2002, October 1st, 2002, January 6th, 2003 and the month of April 2003 due to logistical constraints.

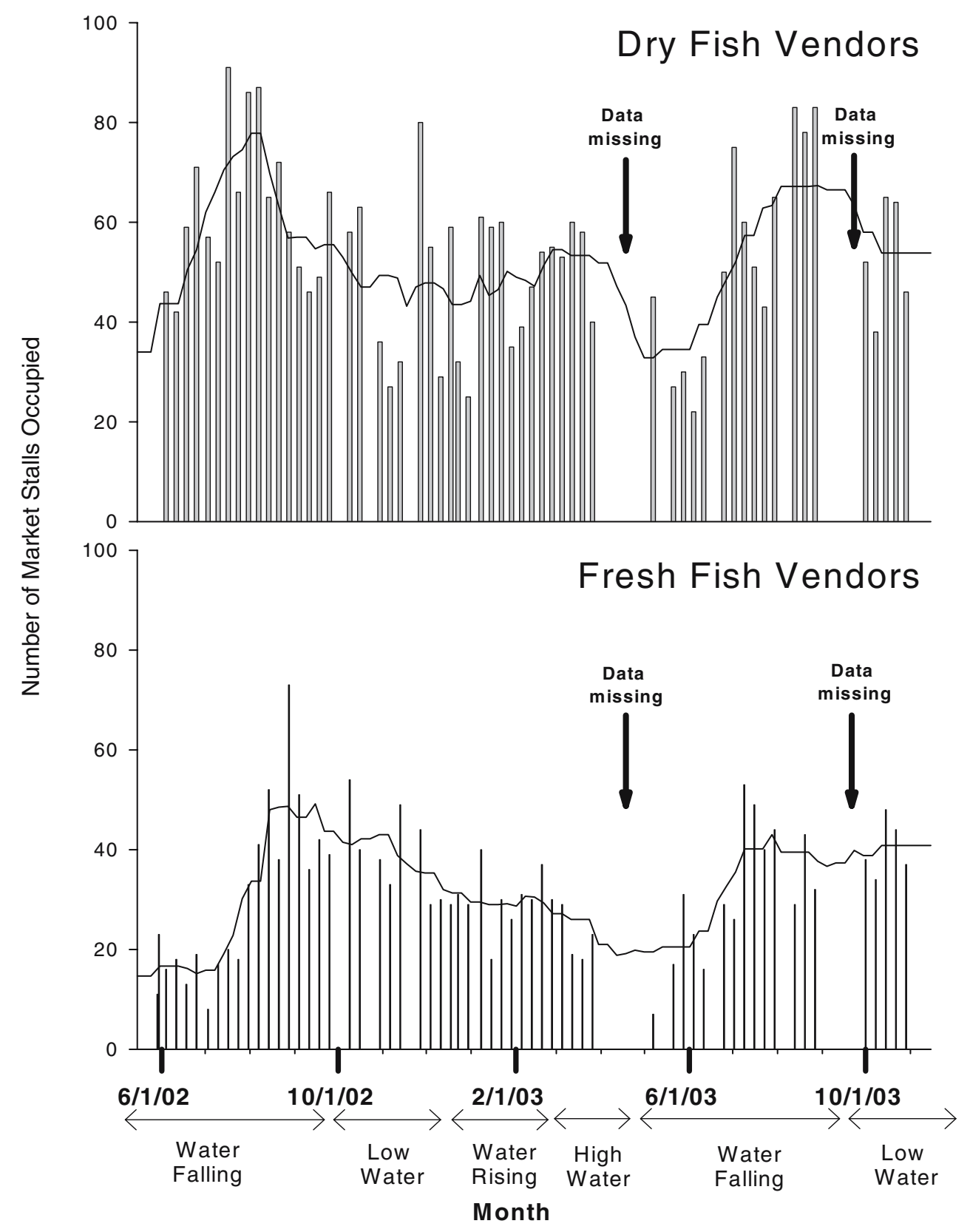

the day, an adjacent vendor will typically look after their stock and sell it on their behalf.

\section{Market Stall Occupation and Vendor Distribution}

The number and type of fish vendors occupying stalls at the market varied during the research period (Fig. 2). Dry fish vendors consistently outnumbered fresh fish vendors on the days sampled except for early September 2002. The highest numbers of both types of vendors recorded during our study coincided with the return of floodwaters to the main channel, the mid- to end of the 'water falling' season. While missing data for April 2003 constrain our ability to determine the low season, there does appear to be an overall dip in the number of both fresh and dry fish vendors during the 'high water' season (Fig. 2).

Fish Species, Length and Price

Given the quantity of data collected on fish species, length and price, results relevant to the research questions of interest in this paper are summarized, rather than presented in full. Seventeen species of fish were found in the market, with no apparent specialization among vendors. Fish were arranged in price intervals by size, with immature individuals of large species grouped with mature individuals of 


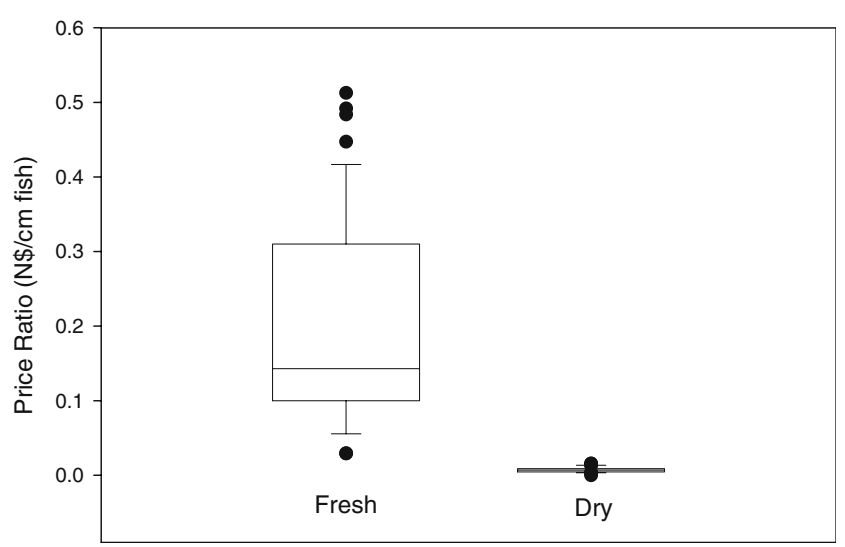

Fig. 3 Price/length ratios $(\mathrm{N} \$ / \mathrm{cm})$ for fresh $(n=49)$ and dry $(n=45)$ Greenhead Tilapia (Oreochromis macrochir), recorded during the December 2002 surveys of the Ngweze market. The boundary of the box closest to zero indicates the 25 th percentile, the line within the box marks the median, and the boundary of the box farthest from zero indicates the 75th percentile. Error bars above and below the box indicate the 90th and 10th percentiles.

small species. The limited influence of species on price was informally confirmed by vendors while measurements were taken, although the larger individuals of some bream species apparently were more desirable due to their taste.

All other factors being equal (such as species and size), dry fish sold for less than fresh fish. For example, Fig. 3 illustrates price/fish length ratios for Greenhead Tilapia (Oreochromis macrochir), sampled in December 2002. While fresh fish is significantly higher priced than dry fish, the price range by length for fresh fish is much wider than the price range by length for dry fish. This difference in pricing between fresh and dry fish holds true for other species (J. Abbott, unpublished data).

\section{Dry and Fresh Fish Vendor Surveys}

A total of 780 structured vendor surveys were conducted between June 2002 and May 2003. From this number, 189 surveys were omitted from analysis because of incomplete answers. Of the remaining 591 surveys, 307 sold fresh fish, 274 sold dry fish, 5 sold a mix of fresh and dry and 4 sold small dried fish known as mbalabala. Of the 101 vendors who expressed a preference for selling fresh or dry fish, 51 preferred to sell fresh fish and 50 preferred to sell dry fish. A small proportion $(7 \%)$ of dry fish vendors stated that they preferred to sell fresh fish, but that they could not afford ice and/or coolers. The rationales behind these preferences showed a marked distinction between fresh and dry. Preferences for fresh fish were either due to the perception that sales were quicker ( $68 \%$ of fresh fish vendors) and profit was greater (54\% of fresh fish vendors). In addition to being able to sell their stock faster, vendors mentioned the excess time involved in drying fish (29\% of fresh fish vendors). By contrast, vendors who preferred to sell dry fish emphasized the lower risk of spoilage $(86 \%)$ and the longer time they could stay at the market (29\%) All fish vendors ranked fish vending as the most important component of their livelihood activities. Investment and expected profit reported by fish vendors showed a broad range of distribution (Fig. 4a and b), although dry fish vendors by percentage reported higher levels of both investment and profit.

\section{Demographic Profile}

Only four sampled vendors were men. Over two-thirds of the fresh fish vendors and just over half of the dried fish vendors stated that they were married (Table I), showing a significant relationship between fish preparation choice and marital status $\left(\chi^{2}=37.34 ; p<0.0001, \mathrm{df}=3\right)$. Just over half of the fish vendors described themselves as the head of the household (i.e., the person responsible for making decisions for the rest of the household) (Table II). A significantly larger proportion of fresh fish vendors $(72 \%)$ described themselves as household heads than dry fish vendors $(38 \%)$ $\left(\chi^{2}=47.24 p<0.0001 ; \mathrm{df}=3\right)$.

\section{Sources of Fish}

Fish vendors got their fish from a variety of sources (Table III). Overall, the most common source of fish was from fishers in the village or the nearby riverbank. A very low proportion of vendors bought their stock directly from another vendor. A significantly higher proportion of fresh fish vendors got their supplies from families than dry fish vendors $\left(\chi^{2}=16.89 ; p<0.001 ; \mathrm{df}=3\right)$. Getting enough fish was the most frequently mentioned factor as having the greatest effect on vendor's ability to sell fish, followed by transportation (Table IV). Few vendors mentioned size or species as an issue. Few dried fish vendors mentioned preparing fish as the most important effect on sales.

\section{Preparation Preference}

A small number (23) of fresh fish vendors surveyed expressed a preference for sizes or species of fish. Of those, 20 vendors said that they liked selling big fish, as it brought more buyers and profit. Only two vendors identified redbreast tilapia (Tilapia rendalii; SiLozi: mbufu) as the preferred species to sell due to its taste. One vendor preferred selling small fish as they were cheaper to get.

\section{Seasonal Variation}

It is difficult to establish any patterns in seasons identified by vendors as the best or worst for selling fish (Tables $\mathrm{V}$ and VI). The season where the water has largely returned to the main river channel or is in isolated pools (low water) 
Fig. 4 a Amount in Namibian Dollars (N\$) invested by Ngweze Market fish vendors interviewed in 2002. Repeat interviews included, $\mathbf{b}$ expected profit in Namibian Dollars (N\$), after deducting market fees, ice and other expenses, reported by Ngweze Market fish vendors interviewed in 2002. Repeat interviews included.
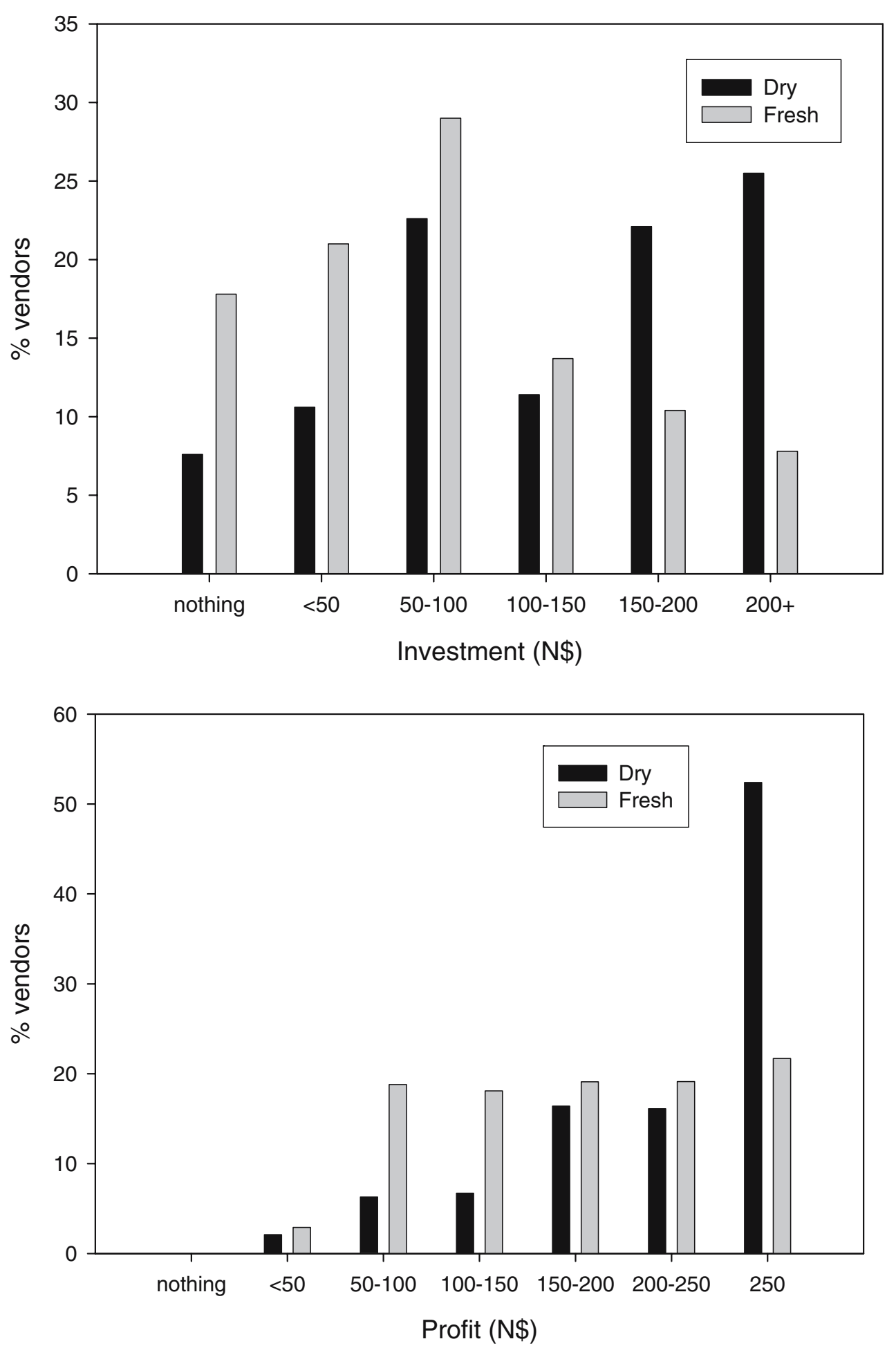

was identified by roughly half of both types of fish vendors as being the best time to sell fish. However, similarly high numbers identified it as the worst time to sell fish. The broad difference of opinion seen in Tables V and VI regarding the best and worst seasons for selling fish is made more evident in the rationales behind vendor perceptions (Table VII). Some vendors view fish scarcity as an advantage and others as a disadvantage. Moreover, scarcity and abundance of fish seem to occur simultaneously to different vendors throughout the year, especially during the high water season. Similarly, high temperatures can allow for quicker drying, but can also lead to spoilage of fresh fish, while the rainy season makes fish drying more difficult. According to the responses, temperature also 
Table I Marital Status of Ngweze Market Fish Vendors Interviewed in 2002

\begin{tabular}{llllr}
\hline & Married & Single & Divorced & Widowed \\
\hline Fresh Fish & $170(77)$ & $41(19)$ & $4(2)$ & $3(1)$ \\
Dry Fish & $102(53)$ & $51(27)$ & $28(15)$ & $9(5)$ \\
Total & $272(66)$ & $92(22)$ & $32(8)$ & $12(3)$ \\
\hline
\end{tabular}

Actual number of vendors is followed by percentages in brackets. Repeat interviews not included.

affects fish behaviour and thus the size of the catch. Vendors stated that high temperatures made the fish "go deep" or "hide in grass," whereas cold temperatures caused fish to move less.

\section{Semi-structured Interviews}

A total of 44 vendors were interviewed, of whom 12 sold fresh fish and 32 sold dry fish. When asked for the reasons why they began selling fish, 29 vendors identified what can be interpreted as 'push' factors (Barrett et al., 2001), such as crop failure, death of spouse, and lack of school fees to continue education. 'Pull' factors were mentioned by three of the vendors, with two saying that they realized that selling fish could be more profitable than what they were doing, and one stating that she wanted to be independent from her family. The remaining ten vendors gave responses that are classified as 'opportunity-driven,' including the willingness of family, especially grandparents, to lend money from their old age pensions. Two vendors mentioned their husbands were part of a fisheries extension project in Zambia in the 1970s that distributed nets to participants.

Almost all of the vendors interviewed had bought the fish they brought to market. Thirty-eight vendors bought from different fishers, while the other six bought from the same fishers all the time. Of the latter, two vendors owned nets and hired people to fish for them. Most vendors explained that they began by simply selling fish from their own family's catch, and then began to buy from other fishers. Several vendors stated that they moved along the

Table II Household Position of Ngweze Market Fish Vendors Interviewed in 2002

\begin{tabular}{lcrcr}
\hline & $\begin{array}{l}\text { Household } \\
\text { Head }\end{array}$ & Spouse & $\begin{array}{l}\text { Child of } \\
\text { Household }\end{array}$ & Other \\
\hline Fresh fish & $156(72)$ & $49(22)$ & $8(4)$ & $5(3)$ \\
Dry fish & $72(38)$ & $96(50)$ & $16(8)$ & $6(3)$ \\
Total & $228(56)$ & $145(35)$ & $24(6)$ & $11(3)$ \\
\hline
\end{tabular}

Actual number of vendors is followed by percentages in brackets. Repeat interviews not included.
Table III Source of Fish Sold by Ngweze Market Fish Vendors Interviewed in 2002 (Respondents Could Identify More than One Source)

\begin{tabular}{lllll}
\hline & $\begin{array}{l}\text { Buy at } \\
\text { Riverside/Village }\end{array}$ & Family & $\begin{array}{l}\text { Travel } \\
\text { along river }\end{array}$ & $\begin{array}{l}\text { Other } \\
\text { Vendor }\end{array}$ \\
\hline Fresh Fish & $218(87)$ & $57(23)$ & $30(12)$ & $2(1)$ \\
Dry Fish & $209(76)$ & $21(8)$ & $41(15)$ & $3(1)$ \\
Total & $427(74)$ & $78(13)$ & $71(12)$ & $5(1)$ \\
\hline
\end{tabular}

Actual number of vendors is followed by percentages in brackets. Repeat interviews included.

floodplain as the season progressed looking for abundant sources of fish. In terms of how the price paid to the fisher was decided, 16 vendors stated that it was a result of mutual negotiation, depending on the size of the fish and the quantity purchased, while seven respondents said that the fisher decided the price and one respondent said she decided herself when asked if fishers always had enough fish for each vendor to buy, they replied that sometimes there wasn't enough. When asked if this led to vendors bidding to get fish, the respondents said that the price didn't change, but those that did not get any fish one time would be first to get fish the next time.

When asked if they liked being a fish vendor, 40 responded yes and 4 responded no. Reasons for preferring to be a fish vendor included the limited investment required, as well as higher, more regular and immediate profits as compared to other options. Those who responded no explained that profits were low and they had no other options. Vendors were also asked if they had seen any changes since they began selling fish. The two vendors who had been in the market the longest (beginning in 1979 and 1982) stated, not surprisingly, that the price of fish had increased and that there are more fish vendors now. A vendor who began in 1982 stated that when Namibia became independent in 1990, prices went up because everybody was being paid more. Those vendors who began selling fish in the 1990s also noted that there were more vendors and the price of fish at the riverside had increased,

Table IV Factors Stated as Having Greatest Effect on Ability to Sell Fish by Ngweze Market Fish Vendors Interviewed in 2002

\begin{tabular}{lrllll}
\hline & $\begin{array}{l}\text { Getting } \\
\text { Enough } \\
\text { Fish }\end{array}$ & Transport & $\begin{array}{l}\text { Preparing } \\
\text { Fish }\end{array}$ & $\begin{array}{l}\text { Getting } \\
\text { Desired } \\
\text { Species }\end{array}$ & $\begin{array}{l}\text { Getting } \\
\text { Desired } \\
\text { Size }\end{array}$ \\
\hline Fresh Fish & $84(60)$ & $49(35)$ & $4(3)$ & $1(1)$ & $2(1)$ \\
Dry Fish & $94(72)$ & $27(21)$ & $9(7)$ & $0(0)$ & $0(0)$ \\
Total & $178(66)$ & $76(28)$ & $13(5)$ & $1(1)$ & $2(2)$ \\
\hline
\end{tabular}

Actual number of vendors is followed by percentages in brackets. Repeat interviews not included. 
Table V Seasons Identified as Best and Worst by Ngweze Market Fresh Fish Vendors Interviewed in 2002

\begin{tabular}{lllll}
\hline & Water Rising & High Water & Water Falling & Low Water \\
\hline Best & $10(8)$ & $31(26)$ & $25(22)$ & $53(45)$ \\
Worst & $13(11)$ & $29(26)$ & $32(28)$ & $41(36)$ \\
\hline
\end{tabular}

Actual number of vendors is followed by percentages in brackets. Repeat interviews not included.

resulting in a decline in profits for some. However, some vendors also noted that the market infrastructure had improved and two said that their own profits had increased due to the fact that they had bought dragnets. Several respondents attributed the rise in numbers of vendors to the fact that the sustained drought since 2000 had caused crop failures and made it more difficult to grow vegetables for the market. This factor was also cited to explain the rise in fishers, although the amount of fish being caught had not really increased, resulting in higher prices and less fish to go around.

\section{Discussion}

In discussing our results, we revisit the four questions posed at the beginning of this paper:

1) What is the commodity chain linking fish to market?

The system of accumulation and distribution that brings fish from the floodplains, to Ngweze Market and ultimately the consumer is very simple. Whereas high numbers of vendors may come to the market, each individual has relatively small amounts of fish. Indepth interviews suggest that most vendors began by selling the family's catch, confirming results of a separate household survey (Abbott, 2005) that most fishing households are also involved in selling fish in the market. The importance of kin-based networks, at least at the outset, as well as the inheritance of vending operations from female relatives is reminiscent of Ghanian bushmeat vending described by Mendelson et al. (2003). However, in-depth interviews revealed that vendors will sometimes migrate, either seasonally or permanently, to other sources of fish, implying that networks are not always kin-based.

An important characteristic that distinguishes the Ngweze Market from African markets described elsewhere in the literature (e.g., Chalfin, 2000; Clark, 1994; Fafchamps, 1997; Geertz, 1978; Marquette et al., 2002, Overå, 2001) is the limited level of organization amongst vendors. The lack of strong market organization may be indicative of the limited prominence of informal markets in general in Namibia. In most areas of the country, the informal market sector is relatively small, with the majority of commerce being carried out either at general stores selling low cost goods imported from China or outlets of South African franchises.

Both Platteau (1989) and Jul-Larsen et al. (2003) suggest that markets associated with small-scale fisheries do not function according to modern economic theory, due to market imperfections on fish availability and price. As traditional markets do not have perfect knowledge about price and availability, participants overcome high transaction costs by personal networks and patronage. The higher the transaction costs, the more traditional linkages make sense, but this in theory limits expansion and accumulation.

As our results indicate, the commodity chain linking fish to the Ngweze Market is certainly characterized by potential variations in availability and price. However, the arrangements that are thought to overcome these constraints, such as patron-client relationships and dedicated supply arrangements, are not apparent in our case study. We discuss the significance of these findings further in regards to Question no. 3.

2) Is market supply largely dictated directly or indirectly by seasonal factors, such as the natural variation in fish abundance or the variability in floodplain livelihoods?

Seasonality potentially has both biological and socioeconomic effects. First, the abundance of fish available for selling is affected by seasonal variation in catch effort. Second, seasonality of other livelihood activities may pose opportunity costs to both fishers and vendors. Market stall occupation results demonstrate that vendors attend the market year-round, although in varying numbers (Fig. 2), but other survey results do suggest that supply was linked at least in part to environmental variation. Vendors ranked finding sufficient amounts of fish as the most frequent constraint (Table IV), and a large number of vendors identified best and worst seasons for selling (Tables $\mathrm{V}$ and VI) and rationales (Table VII) linked to the contrasting environmental characteristics (such as temperature, precipitation and water level) of each season. Fish vendors respond differently to the seasonal fluctuation of fish catch, where abundance and scarcity can be seen either as an advantage or constraint to an individual vendor.

3) How do small-scale fish vendors respond to high apparent levels of uncertainty in fish supply?

Table VI Seasons Identified as Best and Worst by Ngweze Market Dry Fish Vendors Interviewed in 2002

\begin{tabular}{lclll}
\hline & Water Rising & High Water & Water Falling & Low Water \\
\hline Best & $5(4)$ & $36(29)$ & $33(26)$ & $49(40)$ \\
Worst & $18(15)$ & $28(23)$ & $29(24)$ & $48(39)$ \\
\hline
\end{tabular}

Actual number of vendors is followed by percentages in brackets. Repeat interviews not included. 
Table VII Rationales Given by Ngweze Market Fish Vendors Interviewed in 2002 Regarding Choice of Best and Worst Seasons to Sell Fish

\begin{tabular}{|c|c|c|c|}
\hline \multicolumn{2}{|l|}{ Water Rising } & \multicolumn{2}{|l|}{ High Water } \\
\hline Best & Worst & Best & Worst \\
\hline \multirow[t]{4}{*}{ Less fish (6) } & $\begin{array}{l}\text { Rainy season—fish go } \\
\text { bad (12) }\end{array}$ & High water/less fish (30) & Lots of fish (13) \\
\hline & Dry fish rot (2) & $\begin{array}{l}\text { A lot of fish/fish move with the flood } \\
\text { (8) }\end{array}$ & High water (19) \\
\hline & Too many vendors/fish (8) & Cool temperature (4) & $\begin{array}{l}\text { Fish moving around too much, no specific place } \\
\text { to catch them (8) }\end{array}$ \\
\hline & $\begin{array}{l}\text { Too cold for fish to move } \\
\text { (2) }\end{array}$ & Water still moving (3) & \\
\hline Water Falling & & Low Water & \\
\hline Best & Worst & Best & Worst \\
\hline $\begin{array}{l}\text { Cool temperature } \\
\text { (6) }\end{array}$ & $\begin{array}{l}\text { Cool temperature/fish go } \\
\text { deep (23) }\end{array}$ & Less fish (26) & Fish go deep/fish moving around (7) \\
\hline Fish not moving (5) & $\begin{array}{l}\text { Too much fish at the } \\
\text { market (8) }\end{array}$ & High temperatures (20) & High temperature (14) \\
\hline Less fish (7) & & Best time to fish (3) & Less fish (3) \\
\hline Lots of fish (1) & & Fish dry easily (4) & Lots of fish (9) \\
\hline \multirow{2}{*}{$\begin{array}{l}\text { Water high/going } \\
\text { back (9) }\end{array}$} & & Water going back, gone back (17) & \\
\hline & & $\begin{array}{l}\text { Many ways of fishing because the } \\
\text { water is low (2) }\end{array}$ & \\
\hline
\end{tabular}

Frequency of responses given in brackets.

Regardless of the seasonal factors that may drive trends in fish supply, environmental and socioeconomic factors operating on a day-to-day level result in high levels of uncertainty in both the quantity and composition (size and species) of fish available. Vendors at the Ngweze Market adapt to this uncertainty in several ways. To mitigate for uncertainty in fish abundance, vendors obtain fish from a variety of sources (Table III) and in doing so have a better chance of coming across fishers who have sufficient catches. To mitigate for uncertainty of composition, vendors adopt a generalist approach, as reflected in their expressed lack of preference for size or species of fish to sell, and our observations of their catch for sale in market stalls. This reflects the "generalist" characteristic of floodplain fisheries, where a broad range of species and sizes are caught (Welcomme, 1973; 2003). Our results also reflect descriptions by Brummett (2000) of fish markets in Malawi, although supplies there depended on fish caught in nearby lakes, rather than floodplains.

Choosing whether to sell fresh or dry fish is another important adaptation to uncertainty. Given the advantages of either selling fresh fish (e.g., higher prices, faster sales) or dry fish (e.g., less spoilage, higher volume), both types of vendors can adapt to low supplies of fish, although in different ways. Fresh fish vendors who can operate during times of scarcity report higher prices and faster sales (Table VII) and dry fish vendors can accumulate stock over time before going to market. The fresh fish/dry fish distinction is revisited in the discussion of Question no. 4.
Our findings show that specific arrangements for fishers to supply vendors or for drivers to transport fishers to market, arrangements that might help overcome high transaction costs (Platteau, 1989), are mostly absent. This seemingly informal and uncomplicated framework is a reasonable outcome when the amounts of both the commodity and participants can fluctuate on a daily basis. In this way, a fisher is not tied to selling to a specific vendor who may not come that day due to unforeseen circumstances, nor is a vendor obliged to buy only from a specific group of fishers even when their catch is poor.

Small-scale fish vendors did have certain institutional characteristics beyond simple behaviour as independent actors. The majority interviewed claimed that, when purchasing fish at the riverside, they gave priority to those who had left empty-handed the time before. This informal arrangement contrasts with arrangements in villages near Lake Kariba, described by Overå (2003), where the 'first come, first served' rule is enforced by the local village management committee. The behaviour of Ngweze fish vendors may at first seem altruistic, but it is highly rational practice given that neither the fishers nor the vendors will know how much fish there is to sell until the catch is in and the portion for consumption removed ${ }^{1}$. Similarly, the practice of looking after a neighbor's stall and selling on

\footnotetext{
${ }^{1}$ We thank Martin Smith for suggesting this possibility in vendor behaviour.
} 
her behalf while she is away would at first seem to compromise one's own competitive ability; however the reciprocative aspect of the practice makes vending a more flexible activity.

4) Are there any patterns in gender, marital status, household position, incomes or histories of small-scale fish vendors that would characterize it as a marginal or lucrative activity?

The most apparent feature of fish vendors at the Ngweze Market is that they are almost all women. Whereas the majority of vendors reported being married (Table I), a large number also reported being the household head (Table II). These characteristics suggest the fish vending is a marginal activity, as several studies (e.g., Mackinnon, 1998; Gladwin et al., 2001) have suggested that female headed households are likely to be poorer than male-headed households. Furthermore, other studies of small scale vending suggest that men will move into markets when returns become lucrative relative to other activities (Billetoft, 1998; Hapke, 2001). However, the range of investment and profit reported by vendors was broad, suggesting that fish vending is marginal for some but lucrative for others and, regardless of this relative assessment, all vendors interviewed ranked it as their most important livelihood.

The higher proportion of female household heads amongst fresh fish vendors compared to dry fish vendors implies that fresh fish vending is more marginal. Households headed by females in southern Africa, having less social and financial capital, are often the poorest. While our results show that fresh fish sells for more (Fig. 3) and higher profits are frequently mentioned by vendors as an advantage for selling fresh fish, our results also suggest that dry fish vending may be more lucrative (Fig. 4a and b). Dry fish vendors tend to invest more in their stock, therefore needing more capital. A relatively small number of fresh fish vendors are able to invest in large numbers of fish and limit loss (through the use of coolers and ice) as well as assert claims to the most favourable stalls. The substantial price variation in fresh fish (Fig. 3) also implies that returns to fresh fish vendors are not as predictable as the stable, albeit low, returns for dry fish vendors. We therefore concur with the conclusions made by Brockington (2001) and Green (1999) that attempting to classify small-scale vending as either marginal or lucrative is not only impossible, but overlooks the context-specific nature of livelihoods in general.

\section{Conclusion}

Our results suggest that small-scale fish vending in a floodplain environment does drive resource exploitation, but in rather limited ways. Surveyed vendors most frequently cited getting enough fish as the most important constraint to vending, suggesting their demand for fish is unmet. Vendors also indicated that over time, the number of people selling fish has increased. While this may be due largely to an intrinsic increase in population (Mendelsohn and Roberts, 1997), it still results in larger quantities of fish arriving to the market. At the same time, there was little evidence of reinvestment of vending revenue into fishing effort or specialization for certain species or sizes, as seen in the Amazon River fisheries (Batista et al., 1998; McGrath et al., 1993). Similarly, the lack of intermediaries or regional markets means consumption is almost entirely local, and that demand is quickly saturated by a relatively poor population, reminiscent of the 'involuted market', originally described by Geertz (1963), that Jul-Larsen et al. (2003) suggest often occurs in African inland fisheries. Further insight on the potential effect of markets on exploitation can be gained from the length frequency and species diversity of market stock, to be discussed in a forthcoming article. Regardless, current biological surveys suggest that the present levels of exploitation have not had a deleterious effect on fish stocks (Ministry of Fisheries and Marine Resources, unpublished data).

As a livelihood, fish vending is flexible, with vendors responding to natural and social variability in fish supply by maintaining a fluid relationship with fishers, transporters and the market itself. This behavior differs from the more formalized arrangements seen in markets supplied by artisanal fisheries elsewhere (e.g. Marquette et al., 2002; Overå, 2003; 2001; Seixas and Troutt, 2003). Fish vending at the Ngweze Market appears both lucrative and marginal, depending on the particular vendor, although overall dry fish vending appears to be more stable and often more lucrative than fresh fish vending. Regardless of absolute returns, however, vending was ranked as the most important livelihood by all vendors. This is in spite of the fact that the number of vendors present in the market fluctuates, and very few vendors come to market every day. The wide range of investment and demographic backgrounds among vendors indicates a broad level of participation by individuals with varying degrees of involvement and different livelihood abilities and vulnerabilities.

Current fisheries management in the Zambezi floodplain is minimal, but a variety of interventions are being considered. These include restricting where, how and when fishing may take place. Such interventions may have positive (but largely putative) effects for fish biomass. However, our research suggests the impacts of such interventions on vendors need to be carefully considered. For example, given that there is activity in the market year-round and there is no consensus among vendors on the best and worst times to sell fish, it will be difficult to predict the socio-economic impacts of a closed season and these impacts will not be felt evenly 
among vendors. Furthermore, mesh size restrictions that favor the capture of larger fish may lead to the generalist nature of the commodity chain being changed to a more specialized pursuit. The diverse range of vendors with different investment capabilities will be less able to engage with this smaller, albeit more lucrative, fishery, leading to a predominance of vendors who can afford to buy and preserve quality fish. Thus, some of the more marginalized participants in fish vending may be shut out altogether. Given the number of women who participate in fish vending and their role as household providers, the consequences of interventions that restrict their livelihood activities will be widely felt. While fisheries managers often consider the impacts of interventions on fishers, this research demonstrates the importance of moving beyond the waters edge in fisheries management and policy making.

Acknowledgements The research for this article was made possible through funding from the International Research Development Council, the Social Sciences and Humanities Research Council, Canada, Duke University, The World Wide Fund for Nature and USAID-Southern Africa. Our thanks go to the fish vendors and fishers of the Upper Zambezi for their openness and patience.

\section{References}

Abbott, J. G. (2005). Fishing for a living: Subsistence and income uses of a common property resource in the Upper Zambezi floodplains, $\mathrm{PhD}$ Dissertation, Duke University, USA.

Adams, W. (1992). Wasting the Rain: Rivers, People and Planning in Africa. University of Minnesota Press, Minneapolis.

Agrawal, A., and Gibson, C. (1999). Enchantment and Disenchantment: The Role of Community in Natural Resource Conservation. World Development 27(4): 629-649.

Agrawal, A., and Yadama, G. (1997). How Do Local Institutions Mediate Market and Population Pressures on Resources? Forest Panchayats in Kumaon, India. Development and Change 28: 435-465.

Allison, E., and Ellis, F. (2001). The Livelihoods Approach and Management of Small-scale Fisheries. Marine Policy 25(5): 377388.

Allison, E., and Mvula, P. (2002). Fishing Livelihoods and Fisheries Management in Malawi. LADDER Working Paper no. 22. Overseas Development Group, University of East Anglia.

Andersson, J., and Ngazy, Z. (1998). Coastal Communities Production Choices, Risk Diversification, and Subsistence Behavior: Responses in Periods of Transition. Ambio 27(8): 686-693.

Bækgaard, M., and Overballe, H. (1992). When is a fishing man a fisherman? Artisanal fishery development in Guineau-Bissau. In Tvedten, I., and Hersoug, B. (eds.), Fishing for Development: Small-scale Fisheries in Africa, Nordiska Afrikainstitutet, Uppsala, Sweden, pp. 173-190.

Barrett, C., Reardon, T., and Webb, P. (2001). Nonfarm Income Diversification and Household Livelihood Strategies: Concepts, Dynamics and Policy Implications. Food Policy 26: 315-331.

Batista, A., Inhamuns, A., Freitas, C., and Freire-Brasil, D. (1998). Characterization of the Fishery in River Communities of the Low-Solimoes/High Amazon Region. Fisheries Management and Ecology 5: 419-435.
Becker, L. C. (2000). Garden Money Buys Grain: Food Procurement Patterns in a Malian Village. Human Ecology 28(2): 219-250.

Berkes, F., Mahnon R., McConney, P., Pollnac, R., and Pomeroy, R. (2001). Managing Small-scale Fisheries: Alternative Directions and Methods, International Development Research Centre, Ottawa.

Billetoft, J. (1998). Coping with uncertainty-Petty producers in postwar Mozambique. CDR Working Paper, Danish Institute for International Studies, Copenhagen.

Bowen-Jones, E., Brown, D., and Robinson, E. (2003). Economic Commodity or Environmental Crisis? An Interdisciplinary Approach to Analysing the Bushmeat Trade in Central and West Africa. Area 35(4): 390-402.

Brockington, D. (2001). Women's Income and the Livelihood Strategies of Dispossessed Pastoralists Near the Mkomazi Game Reserve, Tanzania. Human Ecology 29(3): 307-338.

Brummett, R. (2000). Factors Influencing Fish Prices in Southern Malawi. Aquaculture 186(3-4): 243-251.

Chalfin, B. (2000). Risky Business: Economic Uncertainty, Market Reforms and Female Livelihoods in Northeast Ghana. Development and Change 31: 987-1008.

Clark, G. (1994). Onions are My Husband: Survival and Accumulation by West African Market Women. University of Chicago Press, Chicago.

De Janvry, A., Fafchamps, M., and Sadoulet, E. (1991). Peasant Household Behaviour with Missing Markets: Some Paradoxes Explained. Economic Journal 101: 1400-1417.

Dolan, C. (2002). Gender and Diverse Livelihoods in Uganda. LADDER Working Paper. No. 10. Overseas Development Group, University of East Anglia, Norwich, UK, p. 30.

Ellis, F. (2000). The Determinants of Rural Livelihood Diversification in Developing Countries. Journal of Agricultural Economics 51 (2): 289-302.

Ensminger, J. (1992). Making a Market: The Institutional Transformation of an African Society. Cambridge University Press, Cambridge.

Fafchamps, M. (1997). Introduction: Markets in Sub-Saharan Africa. World Development 25(5): 733-734.

FAO. (1996). Fisheries and Aquaculture in Sub-Saharan Africa: Situation and Outlook in 1996. Food and Agricultural Organization, Rome.

Geertz, C. (1963). Agricultural Involution: The Process of Ecological Change in Indonesia. University of California Press, Berkeley.

Geertz, C. (1978). The Bazaar Economy: Information and Search in Peasant Marketing. Economics and Anthropology 68(2): 28-32.

Geheb, K., and Sarch, M. (2002). Africa's Inland Fisheries: The Management Challenge. Fountain, Kampala.

Gibbon, P. (1997). Of saviours and punks: The political economy of the Nile perch marketing chain in Tanzania. CDR Working Paper, Danish Institute for International Studies, Copenhagen.

Gladwin, C., Thomson, A., Peterson, J., and Anderson, A. (2001). Addressing Food Security in Africa via Multiple Livelihood Strategies of Female Farmers. Food Policy 26(2): 177-207.

Godoy, R., Guerven, M., Byron, E., Reyes-Garcia, V., Keough, J., Vadez, V., Wilkie, D., Leonard, W., Apaza, L., Huanca, T., and Perez, E. (2004). Do Markets Worsen Economic Inequalities? Kuznets in the Bush. Human Ecology 32(3): 339-364.

Gordon, D. (2003). Technological change and economies of scale in the history of Mweru-Luapula's fishery (Zambia and Democratic Republic of Congo). In Jul-Larsen, E., Kolding, J., Overå, R., Nielsen., J. and Zwieten, P. (eds.), Management, co-management or no management? Major dilemmas in Southern Africa freshwater fisheries. FAO Fisheries Technical Paper 426/2. Food and Agricultural Organization, Rome.

Green, M. (1999). Trading on Inequality: Gender and the Drinks Trade in Southern Tanzania. Africa 69(3): 404-425. 
Hapke, H. (2001). Petty Traders, Gender, and Development in a South Indian Fishery. Economic Geography 77(3): 225-249.

Hilger, P. (2002). Socioeconomic Study for a market precinct at Katima Mulilo, Namibia. Report prepared for Lux-Development, mandated by the Ministry of Foreign Affairs, Cooperation and Humanitarian Aid of the Grand-Duchy of Luxembourg.

Holt, F. L. (2005). The Catch-22 of Conservation: Indigenous Peoples, Biologists and Cultural Change. Human Ecology 33(2): 199-215.

Jentoft, S. (1998). Social science in fisheries management: a risk assessment. In Pitcher, T. J., Hart, P. J. B., and Pauly, D. (eds.), Reinventing Fisheries Management, Kluwer, London, pp. 177-184.

Jul-Larsen, E., Kolding, J., Overå, R., Nielsen., J., and Zwieten, P. (2003). Management, co-management or no management? Major dilemmas in Southern Africa freshwater fisheries. FAO Fisheries Technical Paper 426/1. Food and Agriculture Organization, Rome.

Klein, A. (1999). The Barracuda's Tale: Trawlers, the Informal Sector and a State of Classificatory Disorder off the Nigerian Coast. Africa 69(4): 555-573.

Laë, R. (1997). Does Overfishing Lead to a Decrease in Catches and Yields? An Example of Two West African Coastal Lagoons. Fisheries Management and Ecology 4: 149-164.

Li, T. (2002). Engaging Simplifications: Community-based Resource Management, Market Processes and State Agendas in Upland Southeast Asia. World Development 30(2): 265-283.

Little, P., and Brokensha, D. (1987). Local institutions, tenure and resource management in East Africa. In Anderson, D., and Grove, R. (eds.), Conservation in Africa: People, Policies and Practice, Cambridge University Press, Cambridge, pp. 193-209.

Mackinnon, J. (1998). Can Robust Pro-female Policies be Identified when the True Model of the Household is Unknown? Centre for the Study of African Economies, University of Oxford.

Marquette, C., Koranteng, K., Overå, R., and Aryeetey, E. (2002). Small-scale Fisheries, Population Dynamics, and Resource use in Africa: The Case of Moree, Ghana. Ambio 31(4): 324-336.

McGrath, D. G., de Castro, F., Futemma, C., Domingues de Amaral B., and Calabria, J. (1993). Fisheries and the Evolution of Resource Managment on the Lower Amazon Floodplain. Human Ecology 21(2): 167-195.

Medard, M., Sobo, F., Ngatunga, N., and Chirwa, S. (2001). Women and gender particpation in the fisheries sector in Lake Victoria. Paper presented to the Global Symposium on Women in Fisheries, Kaohsiung, Taiwan.

Mendelsohn, J., and Roberts, C. (1997). An environmental profile and atlas of the Caprivi. Gamsberg Macmillan, Windhoek.

Mendelson, S., Cowlishaw, G., and Rowcliffe, J. (2003). Anatomy of a Bushmeat Commodity Chain in Takoradi, Ghana. Journal of Peasant Studies 31(1): 73-100.

Musambachime, M. (1995). The Role of Kasenga (Eastern Shaba) in the Development of the Mweru-Luapula Fishery. African Studies Review 38(1): 51-68.

Overå, R. (2001). Institutions, mobility and resilience in the Fante migratory fisheries of West Africa. Chr. Michelsen Institute Working Paper 2001:2. Chr. Michelsen Institute, Bergen.

Overå, R. (2003). Market development and investment "bottlenecks" in the fisheries of Lake Kariba, Zambia. In Jul-Larsen, E., Kolding, J., Overå, R., Nielsen., J. and Zwieten, P. (eds.), Management, comanagement or no management?Major dilemmas in Southern Africa freshwater fisheries. FAO Fisheries Technical Paper 426/2. Food and Agricultural Organization, Rome.
Perez, M., Ndoye, O., and Ebeye, A. (2002). A Gender Analysis of Forest Product Markets in Cameroon. Africa Today 49(3): 97-126.

Platteau, J. (1989). Penetration of Capitalism and Persistence of Small-scale Forms in Third-world Fisheries. Development and Change 20(4): 621-651.

Purvis, J. (2002). Fish and livelihoods: Fisheries on the eastern floodplains, Caprivi. DEA Research Discussion Paper. Directorate of Environmental Affairs, Ministry of Environment and Tourism, Windhoek, Namibia.

Rubinoff, J. (1999). Fishing for Status: Impact of Development on Goa's Fisherwomen. Women's Studies International Forum 22 (6): 631-644.

Sarch, M.-T. (1996). Fishing and Farming at Lake Chad: Overcapitalization, Opportunities and Fisheries Management. Journal of Environmental Management 48: 305-320.

Sarch, M., and Birkett, C. (2000). Fishing and Farming at Lake Chad: Responses to Lake-Level Fluctuations. Geographical Journal 166(2): 156-172.

Seixas, C., and Troutt, E. (2003). Evolution of a local Brazilian shrimp market. Ecological Economics 46(3): 399-417.

Shorr, N. (2000). Early Utilization of Flood Recession Soils as a Response to the Intensification of Fishing and Upland Agriculture: Resource-use Dynamics in a Large Tikuna Community. Human Ecology 28(1): 73-107.

Skjønsberg, E. (1992). Men, money and fisheries planning: the case of northern Zambia. In Tvedten, I., and Hersoug, B. (eds.), Fishing for Development: Small-scale Fisheries in Africa, Nordiska Afrikaininstituet, Uppsala, pp. 155-172.

Staal, S., Delgado, C., and Nicholson, C. (1997). Smallholder Dairying Under Transaction Costs in East Africa. World Development 25(5): 779-794.

Tvedten, I., and Hersoug, B. (1992). Introduction. In Tvedten, I., and Hersoug, B. (eds.), Fishing for Development: Small-scale Fisheries in Africa. Nordiska Afrikainstitutet, Uppsala, pp. 7-32.

Vadez, V., Reyes-Garcia, V., Godoy, R., Apaza, V., Byron, E., Huanca, T., Leonard, W., Perez, E., and Wilkie, D. (2004). Does Integration to the Market Threaten Agricultural Diversity? Panel and Cross-sectional Data from a Horticultural-foraging Society in the Bolivian Amazon. Human Ecology 32(5): 635-646.

Vercruijsse, E. (1983). Fishmongers, big dealers and fishermen: cooperation and conflict between the sexes in Ghanaian canoe fishing. In Oppong, C. (ed.), Female and Male in West Africa. George Allen and Unwin, London, pp. 179-191.

Walker, B. L. E. (2001). Sisterhood and Seine-nets: Endangering Development and Conservation in Ghana's Marine Fishery. Professional Geographer 53(2): 160-177.

Welcomme, R. (1973). A Brief Review of the Floodplain Fisheries of Africa. African Journal of Tropical Hydrobiology and Fisheries 1 (1): $67-76$

Welcomme, R. (1999). Fisheries: Enemies of Biodiversity or Tools for Conservation? World Conservation 2: 13-14.

Welcomme, R. (2003). River fisheries in Africa. In Crisman, T., Chapman, L., Chapman, C., and Kaufman, L. (eds.), Conservation, Ecology and Management of African Fresh Waters. University of Florida Press, Gainesville, pp 145-175.

Wilkie, D., and Carpenter, J. (1999). Bushmeat Hunting in the Congo Basin: An Assessment of Impacts and Options for Mitigation. Biodiversity and Conservation 8(7): 927-955.

Winklerprins, A. (2003). Seasonal Floodplain-upland Migration Along the Lower Amazon River. Geographical Review 92(3): 415-431. 